\title{
Endometrial histopathology patterns in women with abnormal uterine bleeding
}

\author{
Anjali Choudhary, Shikha Agarwal, Swati Kohli*, Shweta Mishra, Parul Singh
}

Department of Obstetrics and Gynaecology, Sri. Guru Ram Rai Institute of Medical and Health Services, Patel Nagar, Dehradun, Uttarakhand, India

Received: 06 December 2021

Accepted: 04 January 2022

\section{*Correspondence:}

Dr. Swati Kohli,

E-mail: swatikohli26@gmail.com

Copyright: ( $)$ the author(s), publisher and licensee Medip Academy. This is an open-access article distributed under the terms of the Creative Commons Attribution Non-Commercial License, which permits unrestricted non-commercial use, distribution, and reproduction in any medium, provided the original work is properly cited.

\begin{abstract}
Background: Abnormal uterine bleeding is the most common gynaecological condition for which many women seek medical opinion. Evaluation of these women requires careful investigation into the cause and nature of bleeding with a main focus to exclude organic pathology, especially genital malignancies. Endometrial biopsy is one such intervention which is of immense value in categorizing the conditions. Aims and objectives of current study were to analyse endometrial histology patterns in women with AUB.

Methods: This was a retrospective study conducted on women with AUB who presented in the gynae OPD during the study period of one year and had endometrial biopsy as part of evaluation. Women between with AUB were included in the study after excluding pregnancy related bleeding. Detailed clinical history, examination findings, investigations and endometrial histopathology was noted.

Results: A total of 97 women with AUB who had undergone dilatation and curettage with endometrial biopsy were studied. Majority of women were in age group of 40-45 years and heavy menstrual bleeding was the commonest complaint, AUB (P) 17\% and AUB (L) 39\%, accounted for most of the clinical presentations. Endometrial histology showed varied patterns $27 \%$ had secretory endometrium, $11 \%$ proliferative endometrium. There were 7 cases of endometrial hyperplasia without atypia and three cases of endometrial malignancy.

Conclusions: Histopathological evaluation of endometrium is the cornerstone of management of abnormal uterine bleeding. Endometrial patterns obtained can be useful in ruling out malignancy and help in formulating further management.
\end{abstract}

Keywords: Abnormal uterine bleeding, Endometrial biopsy, Histopathology, Perimenopausal women, PALM-COEIN

\section{INTRODUCTION}

Menstrual irregularities are the commonest complaints for which women seek consultation and comprise about $30 \%$ of gynaecologic out-patient attendees, with an overall prevalence of $10-30 \%$, which may vary between different populations. ${ }^{1}$ Abnormal uterine bleeding (AUB), defined as any abnormality of menstrual bleeding in duration, frequency and amount, can lead to physical debility. ${ }^{2}$ Chronic AUB was defined as 'bleeding from the uterine corpus that is abnormal in volume, regularity and/or timing that has been present for the majority of the last 6 months' according to FIGO 2011 consensus. $^{2}$

According to one study the menstrual disorders account for $19.1 \%$ of 20.1 million visits to gynaecology clinics and about $25 \%$ of gynaecological surgeries are done for AUB. ${ }^{3,4}$ As a clinical entity it can be a cause great deal of physical ,psychological and social stress for these women , and economic loss due to loss of workdays ,affecting quality of their lives..$^{5}$ Due to inconsistencies in nomenclature and classification of menstrual 
abnormality, the clinical approach to this very vital problem has been fragmented till recent times. In 2011 The international federation of obstetricians and gynaecology (FIGO) has introduced a new nomenclature of AUB for menstrual abnormalities and a new classification system to cover all menstrual complaints under the acronym, PALM-COEIN, which this has been widely acknowledged and used. ${ }^{6}$ In accordance to this classification AUB can be classified as (AUB-P) polyp, (AUB-A) adenomyosis, (AUB-L) leiomyoma, (AUB-M) malignancy and hyperplasia, (AUB-C) coagulopathy, (AUB-O)ovulatory dysfunction, (AUB-E) endometrial, and (AUB)I) iatrogenic and (AUB-N) not otherwise classified. ${ }^{2}$ The "PALM" classification refers to structural abnormalities in genital tract, which can be diagnosed visually or by imaging or histo-pathology), whereas the "COEIN" classification denotes non-structural abnormalities.$^{5,7}$ This classification has proven to be very useful and practical in diagnosing and managing cases of AUB.

About 25-30 \% women experience some amount of abnormal bleeding before menopause. About $80 \%$ of these women have anovulatory bleeding. ${ }^{8,9}$ Perimenopausal AUBs usually reflect an organic pathology in the genital tract, like fibroid, polyp, adenomyosis or endometrial hyperplasia due to hormonal causes. ${ }^{10}$ Evaluation of these women requires careful investigation into the cause and nature of bleeding with a main focus to exclude organic pathology, especially genital malignancies. Endometrial biopsy is one such intervention which is of immense value in knowing the aetiology of bleeding abnormality and planning further management. In perimenopausal females since many women might be anovulatory it becomes imperative to rule out endometrial hyperplasia or malignancy. Endometrial histopathological patterns in perimenopausal women range from secretory endometrium to hyperplastic and cystic glandular hyperplasia. With each successive anovulatory cycle the endometrium proliferates under the effect of oestrogen, unopposed by progesterone action and increases in degree and severity, leading eventually to hyperplasia, hyperplasia with atypia and eventually uterine malignancy. Dilatation and curettage are a simple cost-effective investigation of detecting uterine pathology. ${ }^{11}$

\section{Objectives}

Objective of the present study was to analyse endometrial histology to understand patterns and frequency of uterine pathology in perimenopausal women with AUB.

\section{METHODS}

This was a retrospective study into analysis of women with AUB who presented in the gynaecology OPD of SGRRIM and HS and Shri. Mahant Indiresh hospital Dehradun, during the study period of one year from May 2019 to April 2020 and had endometrial biopsy as part of evaluation. Women between 35-55 years of age group with AUB were included in the study after excluding pregnancy related vaginal bleeding. Detailed clinical history with examination findings and the relevant routine and special investigation of these women were noted. History of co-morbidities were enquired and investigated. Ultrasonographic findings of pelvic organs and histo-pathology of endometrial biopsies of the cases, obtained by dilatation and curettage was noted. After evaluation the AUB was classified according to PALMCOEIN classification. Data so obtained were tabulated and analysed.

\section{RESULTS}

A total of 97 women in the age group 40-50 with AUB who had undergone dilatation and curettage for endometrial biopsy were included in the study. Majority of women were in the age group 40 and above (77.2\%) and $89.5 \%$ were of parity two and above. Clinically $43.2 \%$ presented with heavy menstrual bleeding, $22.5 \%$ with frequent menses, $9 \%$ had frequent and heavy periods and $9 \%$ women had dysmenorrhea as an associated complaint.

Table 1: Age group distribution.

\begin{tabular}{|lll|}
\hline Age group (years) & $\mathbf{N}$ & $\%$ \\
\hline $\mathbf{3 6 - 4 0}$ & 22 & 22.6 \\
\hline $\mathbf{4 1 - 4 5}$ & 31 & 31.9 \\
\hline $\mathbf{4 6 - 5 0}$ & 24 & 24.7 \\
\hline $\mathbf{5 0 +}$ & 20 & 20.6 \\
\hline
\end{tabular}

Table 2: Parity distribution.

\begin{tabular}{|lll|}
\hline Parity & N & \% \\
\hline $\mathbf{0}$ & 5 & 5.1 \\
\hline $\mathbf{1}$ & 5 & 5.1 \\
\hline $\mathbf{2}$ & 36 & 37.1 \\
\hline $\mathbf{3}$ & 29 & 29.8 \\
\hline $\mathbf{4}$ & 20 & 20.6 \\
\hline $\mathbf{5 +}$ & 2 & 2.0 \\
\hline
\end{tabular}

Table 3: Clinical features.

\begin{tabular}{|lll|}
\hline Clinical features & N & $\%$ \\
\hline Frequent menses & 22 & 22.6 \\
\hline Hmb & 42 & 43.2 \\
\hline Infrequent menses & 5 & 5.1 \\
\hline Frequent menses with hmb & 9 & 9.2 \\
\hline Intermenstrual spotting & 10 & 10.3 \\
\hline Dysmenorrhea & 9 & 9.2 \\
\hline
\end{tabular}

Clinical examination and ultrasonography and endometrial biopsies were done for all women as a part of evaluation and to classify the pathology according to PALM COEIN method of classification. 38\% fibroids AUB (L), 17\% polyps, AUB (P), 11\% had adenomyosis 
AUB (A), 3\% had was diagnosed as malignancy after endometrial biopsy.

Table 4: BMI.

\begin{tabular}{|lll|}
\hline BMI & N & $\%$ \\
\hline$<18.5$ & 0 & 0 \\
\hline $\mathbf{1 8 . 5 - 2 4 . 9}$ & 24 & 24.7 \\
\hline $\mathbf{2 5 - 2 9 . 9}$ & 58 & 59.7 \\
\hline$>\mathbf{3 0 . 0}$ & 15 & 15.4 \\
\hline
\end{tabular}

Table 5: AUB According to PALM-COEIN.

\begin{tabular}{|lll|}
\hline PALM-COEIN & $\mathbf{N}$ & $\%$ \\
\hline Polyp & 17 & 17.5 \\
\hline Adenomyosis & 11 & 11.3 \\
\hline Leiomyoma & 38 & 39.1 \\
\hline Malignancy & 3 & 3.0 \\
\hline Coagulopathy & - & - \\
\hline Ovulatory dysfunction & 12 & 12.3 \\
\hline Endometrium & 12 & 12.3 \\
\hline Iatrogenic & - & - \\
\hline Not yet classified & 4 & 4.1 \\
\hline
\end{tabular}

Table 6: Endometrial histopathology.

\begin{tabular}{|lll|}
\hline Histopathology & $\mathbf{N}$ & $\%$ \\
\hline Secretory endometrium & 27 & 27.8 \\
\hline Proliferative endometrium & 11 & 11.3 \\
\hline Irregular ripening & 17 & 17.5 \\
\hline Irregular shedding & 10 & 10.3 \\
\hline Endometritis & 4 & 4.1 \\
\hline $\begin{array}{l}\text { Endometrial hyperplasia } \\
\text { without atypia }\end{array}$ & 7 & 7.2 \\
\hline Malignancy & 3 & 3.0 \\
\hline Atrophic endometrium & 2 & 2.0 \\
\hline Luteal phase defect & 4 & 4.1 \\
\hline Hormonal changes & 12 & 12.3 \\
\hline
\end{tabular}

There were $12.3 \%$ cases of ovulatory dysfunction as evident by proliferative endometrium AUB (O), 12.3\% had endometrial hyperplasia AUB (E), and 4,1\% were not classified AUB $(\mathrm{N})$. There was no case of coagulatory AUB (C) or iatrogenic AUB (I) disorder in our study. Endometrial histopathology revealed a variety of patterns, most common was secretory endometrium $27.8 \%$, followed by irregular ripening (17.2\%), proliferative endometrium $(11.3 \%)$, Irregular shedding endometrium (10.3\%).12\% endometrial biopsies showed hormonal changes, $2 \%$ of women had atrophic endometrium and $3.1 \%$ women had endometritis. There were $7 \%$ cases of endometrial hyperplasia without atypia and $3 \%$ biopsies had features of endometrial malignancy.

\section{DISCUSSION}

AUB is a special category of gynaecological disorder that needs careful evaluation to know the cause of bleeding and formulate prospective management. Many of these bleeding patterns are transient and are result of hormonal imbalance peculiar to this age group, and may not require active treatment. More emphasis in these cases is to rule out sinister endometrial hyperplasia and malignancies by endometrial biopsies. Peri-menopausal AUB was found to be at a very high prevalence of $54 \%$ in study by Gopalan and co-workers. ${ }^{12}$ Many menstrual patterns are observed in these women ranging from scanty bleeding to heavy menstrual bleeding, frequent menses and bleeding with severe dysmenorrhea. Commonest complaint in these women is heavy menstrual bleeding, which is most bothersome and leads to anaemia, fatigue and physical debility. We found $43.2 \%$ cases of HMB in our study, there were $22.1 \%$ women with frequent menses and $9 \%$ with severe dysmenorrhea with HMB. In a study by Zeeba S. in analysing 628 women with AUB they found $41 \%$ women presented with menorrhagia, followed by 18 $\%$ metro-menorrhagia. ${ }^{11}$ In another study by Shree Laxmi etal $83 \%$ of women had heavy menstrual bleeding and 26 $\%$ had frequent periods. ${ }^{12}$ While evaluating endometrial histology in perimenopausal women with AUB Archana $\mathrm{B}$ et al. found that $53.3 \%$ women presented with menorrhagia, $28.2 \%$ with polymenorrhagia, $12.2 \%$ had intermenstrual bleeding and $6.5 \%$ had metrorrhagia. In their study dysmenorrhea was common associated symptom in women in 40-45 age group. ${ }^{13}$ In our observation there were $42 \%$ women with heavy menstrual bleeding in this age group, $34 \%$ of these women were moderately, and $11 \%$ were severely anaemic.

Many women with AUB have other comorbidities in the perimenopausal age group which contributes to additional risk factor for endometrial pathology. It has been suggested that about $50 \%$ of women with AUB and hyperplastic endometrium have somatic co-morbid conditions, most common being, obesity, metabolic syndrome, gastrointestinal and cardiovascular diseases. ${ }^{14}$ In our study we found 57.2 overweight and $15.4 \%$ obese according their BMI. Obesity, 9.4\% Diabetes, $11 \%$ hypertension, 17.1 thyroid disease. In a study by Siriwan et al. they found $65 \%$ women with a mean age of 52 years, diagnosed with endometrial cancer had co-existing medical condition, of which metabolic syndrome was the commonest followed by, thyroid disorder. ${ }^{15}$

Pelvic ultrasonography and endometrial biopsy are of immense value in women with AUB under evaluation. In our study we were able to diagnose $62.7 \%$ women with genital tract pathology on, 39.1\% had fibroid (AUB-L), $11.3 \%$ with adenomyosis (AUB-A) and -12.3 women had hyperplastic endometrium (AUB-E) on USG scans. Dilatation and curettage with endometrial sampling are an easy and cost-effective way of assessing endometrial pathology with minimal complications and has become an essential tool in AUB evaluation especially in the perimenopausal women. ${ }^{14,16,17}$ ACOG recommends endometrial biopsy in any woman above 35years of age with anovulatory bleeding not responding to medical 
treatment. ${ }^{18}$ In perimenopausal AUB endometrial biopsy is $82.3 \%$ sensitive in diagnosing endometrial hyperplasia and $91 \%$ sensitive in detecting endometrial cancer with $98 \%$ specificity. ${ }^{19,20}$

Perimenopause is period of great hormonal change for women associated with declining ovarian reserve. Few years before menopause, and cessation of ovarian function, the endometrium and menstrual cycles undergoes many changes ranging from secretory endometrium, luteal phase defects as seen by irregular ripening and irregular shedding endometrium, anovulation- as seen by proliferative endometrium and endometrial hyperplasia. In our study endometrial biopsies were done as a part of routine assessment and yielded varied results the commonest endometrial patterns in our study were, secretory endometrium $27.8 \%$, proliferative endometrium $11.3 \%, 17 \%$ irregular ripening and $11 \%$ irregular shedding. Endometrial hyperplasia was found in $7.3 \%$ and hormonal effect in $12.1 \%$. There were three cases of endometrial malignancy. These changes in endometrium follow a progression of hormonal changes characteristic to perimenopausal age group. Other endometrial patterns in our study were endometritis in $4.1 \%$ and atrophic endometrium in $2 \%$.

In many other studies, predominant endometrial patterns found in perimenopausal women were proliferative endometrium secretory endometrium and endometrial hyperplasia. ${ }^{14,20,21}$ Baral and colleagues while studying endometrial samples categorised irregular shedding and irregular shedding, decidualization and pill effect as abnormal physiological changes. In this study the 40-45 years old women, they found $45 \%$ endometrial samples with normal physiologic and premalignant conditions. ${ }^{22}$ Another similar study of clinical spectrum and histopathological patterns of peri-menopausal AUB found that prevalence of proliferative endometrium was $31.33 \%$, secretory endometrium was $21.67 \%$, atrophic endometrium in $6 \%$. There was endometritis in $8.67 \%$ and adenocarcinoma in $1.6 \% .^{23}$

As a most common troublesome gynaecological disorder, this can be debilitating for some women, abnormal uterine bleeding demands systematic evaluation. Although the diagnostic procedures and treatment modalities have been evolving over time, basic dilatation and curettage to sample endometrium for histopathology remains most important intervention. Understanding endometrial pathology helps in deciding treatment options. Many physiological and benign changes can be left alone till attainment of natural menopause. Some women may be selected for appropriate medical therapy and only a few with sinister endometrial pattern or malignancy require hysterectomy.

\section{CONCLUSION}

Histopathological evaluation of endometrium is the cornerstone of management of women with abnormal uterine bleeding. Endometrial histopathology patterns obtained can help in formulating further management and to rule out malignancy.

Funding: No funding sources Conflict of interest: None declared

Ethical approval: The study was approved by the Institutional Ethics Committee

\section{REFERENCES}

1. Sun Y, Wang Y, Mao L, Wen J, Bai W. Prevalence of abnormal uterine bleeding according to new International Federation of Gynecology and Obstetrics classification in Chinese women of reproductive age: A cross-sectional study. Medicine (Baltimore). 2018;97(31):e11457.

2. Munro MG, Critchley HO, Fraser IS. The flexible FIGO classification concept for underlying causes of abnormal uterine bleeding. Semin Reprod Med. 2011;29:391-9.

3. Albers JR, Hull SK, Wesley RM. Abnormal Uterine Bleeding. Am Fam Physician. 2004;69(8):1915-26.

4. Nicholson WK, Ellison SA, Grason H, Powe NR. Patterns of ambulatory care use for gynaecologic conditions: a national study. Am J Obstet Gynecol. 2001;184:523-30.

5. Whitaker L. Abnormal uterine bleeding. Best Pract Res Clin Obstet Gynaecol. 2016;34:54-65.

6. Baird DD, Dunson DB, Hill MC. High cumulative incidence of uterine leiomyoma in black and white women: ultrasound evidence. Am J Obstet Gynecol. 2003;188:100-7.

7. Brahma PK, Martel KM, Christman GM. Future directions in myoma research. Obstet Gynecol Clin North Am. 2006;33:199-224.

8. Indrani M, Rao PS, Nataraj S, Biswas M. An analysis of endometrial bleeding patterns in perimenopausal women. IJRCOG. 2017;6(7):415-9.

9. Agarwal P, Garg R, Rai N, Prakash P. Abnormal Uterine Bleeding. J South Asian Feder Menopause Soc. 2016;4(1):22-6.

10. Talukdar B, Mahela S. Abnormal uterine bleeding in perimenopausal women: Correlation with sonographic findings and histopathological examination of hysterectomy specimens. J Midlife Health. 2016;7(2):73-77.

11. Jairajpuri ZJ, Rana S, Jetle S. Atypical uterine bleeding-Histopathological audit of endometrium A study of 638 cases. Al Ameen J Med Sci. 2013;6(1): 21-8.

12. Sreelakshmi U. Uterine bleeding in perimenopausal women. Int J Reprod Contracept Obstet Gynecol. 2018;7(1):192-7.

13. Bhosle A, Fonseca M. Evaluation and histopathological correlation of abnormal uterine bleeding in perimenopausal women. Bombay Hosp J. 2010;52(1):60-71.

14. Gopalan U, Rajendiran S, Karnaboopathy R. Study of endometrial histopathology in women with 
abnormal uterine bleeding. Int $\mathbf{J}$ Reprod Contracept Obstet Gynecol. 2017;6(3):824-8.

15. Fetesku SA. Comorbidities in patients with endometrial hyperplasia. Lik Sprava. 2015;(1-2):1579.

16. Tangitagawal S, Khunnarong J, Srijaprachoren S. Medical morbidities in endometrial cancer patients. Int J Gynecol Cancer. 2014;24(9):45-9.

17. Gordon P. Videos in clinical medicine. Endometrial biopsy. N Engl J Med. 2009;361(26):e61.

18. Sweet MG, Schmidt-Dalton TA, Weiss PM, Madsen KP. Evaluation and management of abnormal uterine bleeding in premenopausal women. Am Fam Physician. 2012;85(1):35-43.

19. Doraiswami S, Johnson T, Rao S, Rajkumar A, Vijayaraghavan J, Panicker VK. Study of endometrial pathology in abnormal uterine bleeding. J Obstet Gynecol India. 2011;61(4):426-30.

20. van Dongen H, de Kroon CD, Jacobi CE, Trimbos JB, Jansen FW. Diagnostic hysteroscopy in abnormal uterine bleeding: a systematic review and metaanalysis. BJOG. 2007;114(6):664-75.
21. Khare A, Bansal R, Sharma P, Elhence N. Morphological spectrum of endometrium in patients presenting with Dysfunctional uterine bleeding. People's J Scientific Res. 2012;5:13-6.

22. Baral R, Pudasaini S. Histopathological pattern of endometrial samples in abnormal uterine bleeding. J Pathol Nepal. 2011;1:13-6.

23. Golecha N, Porwal V. Abnormal uterine bleeding: A study of its clinical spectrum and incidence of histopathological patterns of endometrium as a function of age with parity. Indian J Obstet Gynecol Res. 2018;5(3):339-43.

Cite this article as: Choudhary A, Agarwal S, Kohli S, Mishra S, Singh P. Endometrial histopathology patterns in women with abnormal uterine bleeding. Int J Reprod Contracept Obstet Gynecol 2022;11:477-81. 